\title{
Catalytic Cracking of Waste Polypropylene in a Nitrogen Fluidized Bed Reactor
}

\author{
Anil Vyas ${ }^{1}$, Suresh Kumar Singh², Komal Sharma ${ }^{3}$, Sukhwant Singh ${ }^{2}$ \\ ${ }^{1}$ Chemical Engineering Department, Jai Narain Vyas University, Jodhpur, India \\ ${ }^{2}$ Civil Engineering Department, Jai Narain Vyas University Jodhpur, India \\ ${ }^{3}$ Chemical Engineering Department, MNIT, Jaipur, India \\ Email: anilvyas.jnvu@gmail.com
}

Received 13 January 2016; accepted 6 April 2016; published 11 April 2016

\begin{abstract}
Polypropylene (PP) is rated first as volume leader in the plastic sector. Its non-biodegradable property poses serious environmental problem in case of disposal. The catalytic cracking of PP was performed with various catalysts i.e. ZSM-5, Zeolite, RB and SPS. The cracking was observed under different feed to catalyst ratio i.e. 1:1 to 5:1. The fluidized bed reactor was fabricated with arrangement to measure the temperature ranging from $100^{\circ} \mathrm{C}$ to $800^{\circ} \mathrm{C}$. The effective of feed to catalyst ratio was found $3: 1$ at a temperature range of $420^{\circ} \mathrm{C}-510^{\circ} \mathrm{C}$ and catalyst ZSM-5 gives maximum liquid conversion of waste PP. Conversion of PP to liquid fuel will not only resolve the problem of disposal of waste polypropylene plastic but also give a value aided product.
\end{abstract}

Keywords

Waste PP, Pyrolysis, Catalytic Cracking, ZSM-5, Zeolite, Liquid Fuel

\section{Introduction}

Plastics are ubiquitous materials and due to cheap in cost, plastics are discarded easily and its long life means it survives in the environment for long periods. That is why the amount of plastic waste is steadily increasing. Appropriate innovative methods for recycling plastic waste have been developed and new recycling approaches are being investigated [1]. The technology objective is sustainable livelihood within the limited natural \& financial resources and less impact on the environment. World Wide Plastic Industries witnessed a steady growth; Asia has been the world's largest plastic consumer for several years, accounting for about $30.0 \%$ of the global consumption excluding Japan, which has share of about 6.5\%. Next to Asia is North America with $26.0 \%$ share and then Western Europe with $23.0 \%$ share in the global market. India has witnessed a substantial growth in the consumption of plastic which becomes waste significant part of the total municipal solid waste (MSW). It is estimated that approximately 10 thousand tons per day (TPD) of plastic waste is generated i.e. $9.0 \%$ of 1.20 lacs TPD of municipal solid waste (MSW) in India [2]. The thermoplastics are recyclable plastics which include Poly Ethylene Terephthalate (PET), Low Density Poly Ethylene (LDPE), Poly Vinyal Choloride (PVC), High Density Poly Ethylene (HDPE), Polypropylene (PP), Polystyrene (PS), etc. Conversion of plastics waste into liquid fuel describes a range of plastic recovery techniques to make plastics, which break down polymers into their 
constituent monomers, which in turn can be used again in refineries, or petrochemical and chemical production. In the process of catalytic conversion of waste, plastics into fuels due to random de-polymerization occurs in the temperature range of $250^{\circ} \mathrm{C}$ to $550^{\circ} \mathrm{C}$ in absence of oxygen. A range of technologies are currently being explored. These include pyrolysis, hydrogenation, gasification and thermal cracking. The present work was under taken with two fold objectives firstly to dispose of PP and secondly to obtain end products having some economic values if possible [2].

\section{Methods \& Methodology}

Waste PP is found in different shapes and sizes as such pretreatment of waste PP is necessary for uniform feed to the reactor. Cracking of the feed, yields both condensable and non-condensable gases at ambient temperature. Following steps were in the experiment involved pre treatment of feed, fabrication of reactor, thermal catalytic cracking and condensation of product gases.

\subsection{Pre Treatment of Feed}

The municipal plastic waste (containing PP) was used in the experiment. It was collected from a local recovery center of Jodhpur city, India. Materials were sorted out into different categories as per shapes \& sizes. Material of suitable sizes \& shapes were prepared by crushing, cutting \& shredding. The crushed and sized material were heated to $100^{\circ} \mathrm{C}$ and then cooled to atmospheric temperature. The lumps so obtained were crushed $\&$ sieved to obtain uniform particle size of $\leq 2 \mathrm{~mm}$.

\subsection{Catalysts}

The catalysts used were locally available Red Brick Sand, naturally occurred Zeolite \& ZSM-5. Some experiments were also performed using sludge obtained from pickling liquor (SPS), waste product of stainless steel in Jodhpur. The sludge essentially contains small percentage of oxide of Nickel, Chromium \& Iron, after washing with water to remove free acid.

\subsection{Fabrication of Reactor}

The reactor was developed on the basis of technical considerations, mainly its heat transfer, feed and residue handling characteristics. Reaction temperature influence thermodynamics \& kinetics of decomposition of plastic obtained and also the nature of feed \& residue obtained at the end of reaction. High temperatures and heating rates, low pressures and residence times favour the formation of primary products. On the contrary, long detention times lead to a preponderance of stable products. Temperature is the most important variable, since it determines both the rate of thermal decomposition and reaction products. High temperature $\left(>600^{\circ} \mathrm{C}\right)$ and product dilution favour the production of simple small gaseous molecules, low temperature $\left(<400^{\circ} \mathrm{C}\right)$ and increased pressure lead to more viscous liquid products, higher rates of pyrolysis, a higher coking tendency, more secondary products and dehydrogenation. Pyrolysis or gasification, as a process, is much easy to control than direct firing of plastics. The later is impossible on mechanical grates, equipping conventional incinerators for municipal solid waste (MSW). On the other hand, thermal conversion is feasible by means of fluidized bed technology [1] [3]-[15]. In the present work semi batch fluidized bed reactor was fabricated as shown in Figure 1. The reactor has following parts like-Reactor body, sieve plate assembly, feed gas port, feed point, pressure gauge and thermocouples sleeve, heating coil etc. Following parameters were studied- Effect of catalysts, \& Effect of Feed to catalysts ratio.

\subsection{Experimental Setup}

Fabricated reactor as shown in Figure 1 was installed in Chemical Engineering Department, Faculty of Engineering, Jai Narain Vyas University, Jodhpur, India for carried out experiment.

\section{Observations}

The main objective of this study was to get optimum yield of liquid product at optimum temperature. To achieve 
these objectives following parameters were taken as variables:

1) Effect of catalysts (ZSM-5, Zeolite, RB \& SPS).

2) Effect of Feed to Catalysts ratio (F:C: 1:1, 2:1, 3:1, 4:1 \& 5:1) at the same time following constituents were kept fixed throughout the study.

3) Throughout all experiment Nitrogen gas was passed through reactor with flow rate of 9.0 lph (Flow rate of nitrogen was separately studied and found that 9.0 lph was appropriate to keep the catalysts bed fluidized).

4) Total quantity of feed and catalysts was fixed to $200 \mathrm{gm}$.

\section{Result and Discussion}

Experiments were performed using specific catalyst (ZSM-5, Zeolite, RB and SPS), varying the feed to catalysts ratio (1:1 to 5:1) as shown in Figures 2-5. From Figures 2-5 it can be seen that for any given feed to catalyst ratio as temperature increases liquid yield also increases initially. On further increase in temperature maximum yield was obtained between temperature ranges of $370^{\circ} \mathrm{C}-410^{\circ} \mathrm{C}$. Further increase in temperature liquid yield reduces sharply. Beyond $425^{\circ} \mathrm{C}$ cracked product was non-condensable gases.

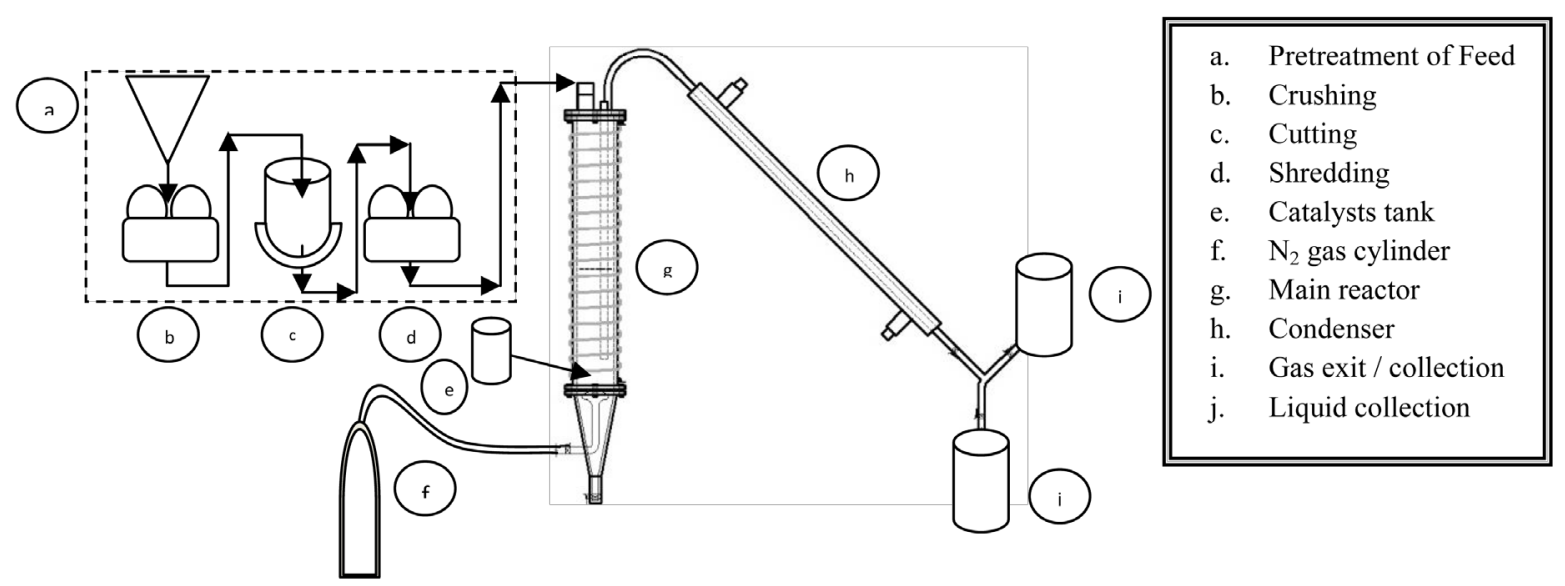

Figure 1. Sketch up of experimental setup [1].

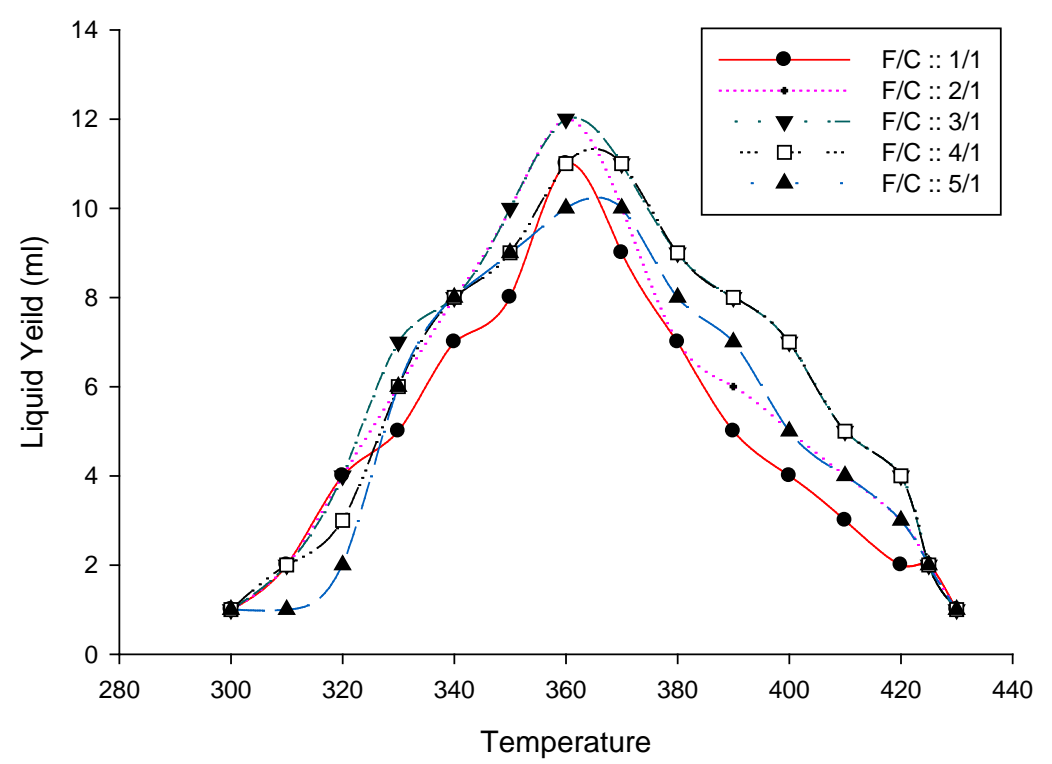

Figure 2. Effect of variation of feed (PP) to catalyst ratio on liquid yield with ZSM-5 Catalyst. 


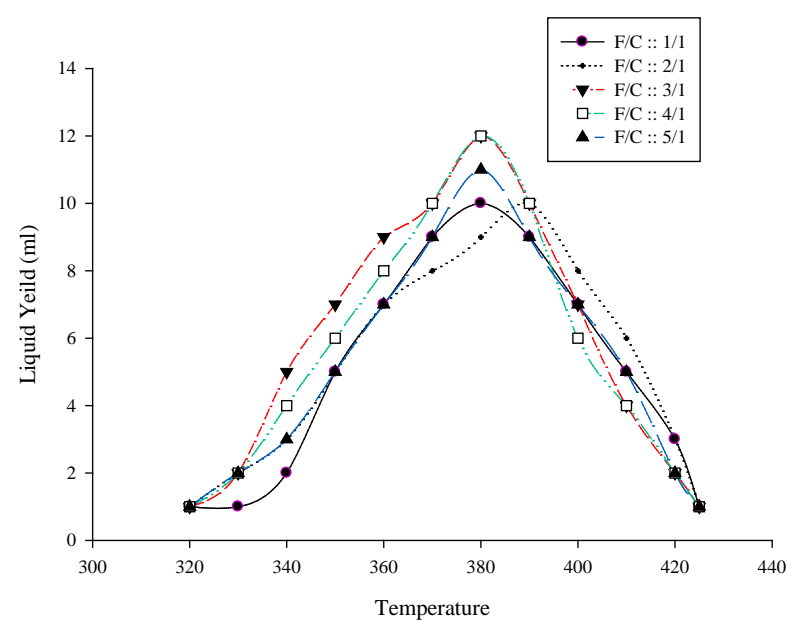

Figure 3. Effect of variation of feed (PP) to catalyst ratio on liquid yield with Zeolite Catalyst.

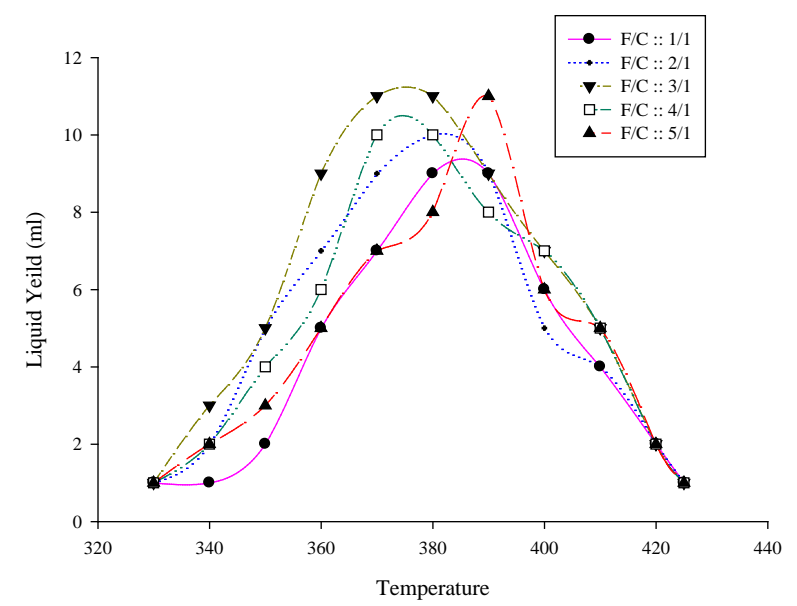

Figure 4. Effect of variation of feed (PP) to catalyst ratio on liquid yield with RB Catalyst.

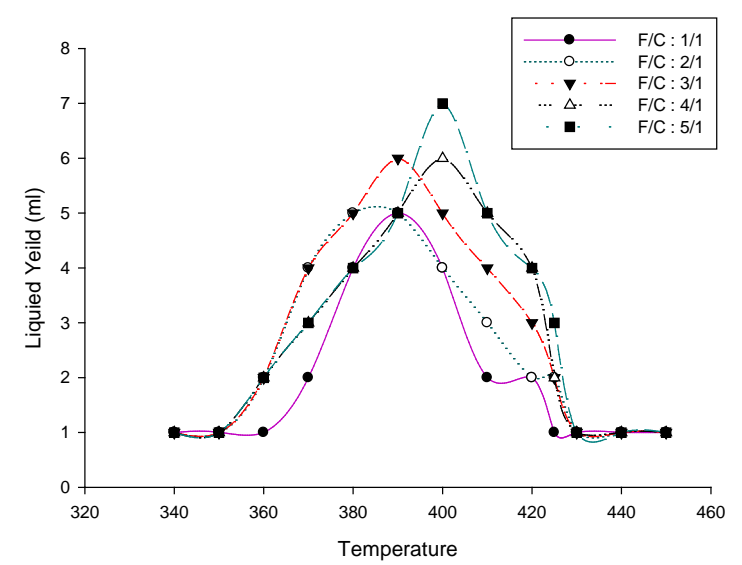

Figure 5. Effect of variation of feed (PP) to catalyst ratio on liquid yield with SPS Catalyst. 
It can be seen from Figure 6 and Table 1 that as feed to catalyst ratio increases from 1:1 to 3:1 the maximum product liquid yield increases, further increase in feed to catalyst ratio from 3:1 to 5:1 liquid yield drops. With catalyst ZSM-5 total yield increases from $70.69 \%$ to $84.67 \%$ thereafter it dropdown from $84.67 \%$ to $57.25 \%$. Using Zeolite the liquid yield increase from $51.32 \%$ to $60.10 \%$ then dropdown from $60.10 \%$ to $53.15 \%$, while using the RB as catalyst the liquid yield increase from $38.40 \%$ to $47.85 \%$ then dropdown from $47.85 \%$ to $30.91 \%$ but with SPS percentage of liquid yield increases as feed to catalyst increases but amount of obtained liquid is very low. It seems likely the lower yield obtained using SPS in the temperature range is more because of thermal cracking rather than the effect of catalyst. The physical properties of product liquid sample obtained by PP cracking are shown in Table 2.

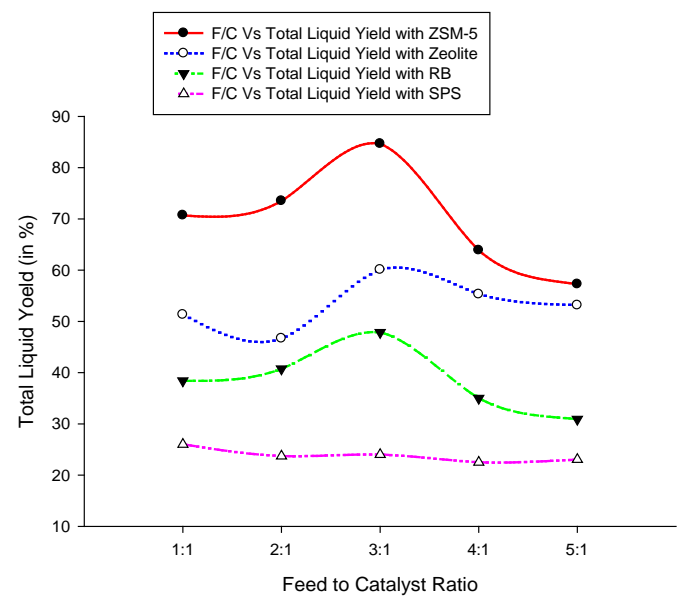

Figure 6. Total liquid yield $\left(\mathrm{y}_{\mathrm{t}}\right)$ (From PP) with different Catalysts.

Table 1. Percentage liquid yield obtained from PP cracking with different catalysts.

\begin{tabular}{ccccc}
\hline & \multicolumn{4}{l}{ Total liquid yield (\%) with Particular Catalyst } \\
\hline F/C Ratio & ZSM-5 & Zeolite & RB & SPS \\
$1: 1$ & $70.69 \%$ & $51.32 \%$ & $38.40 \%$ & $26.00 \%$ \\
$2: 1$ & $73.50 \%$ & $46.67 \%$ & $40.74 \%$ & $23.70 \%$ \\
$3: 1$ & $84.67 \%$ & $60.10 \%$ & $47.85 \%$ & $24.00 \%$ \\
$4: 1$ & $63.87 \%$ & $55.30 \%$ & $35.00 \%$ & $22.50 \%$ \\
$5: 1$ & $57.25 \%$ & $53.15 \%$ & $30.91 \%$ & $23.03 \%$ \\
\hline
\end{tabular}

Table 2. Physical properties of sample obtained by PP cracking.

\begin{tabular}{cc}
\hline Properties & Fuel extracted from waste PP \\
\hline Color, Visual & Pale Yellow \\
Boiling Point & $145^{\circ} \mathrm{C}-155^{\circ} \mathrm{C}$ \\
Specific Gravity $\left(\right.$ at $\left.28^{\circ} \mathrm{C}\right)$ & 0.7716 \\
Gross Calorific Value & $9964 \mathrm{~kJ} / \mathrm{m}^{3}$ \\
Net Calorific Value & $9941 \mathrm{~kJ} / \mathrm{m}^{3}$ \\
API Gravity & 58.05 \\
Sulphur Content & 0.000 \\
Flash Point \& Fire Point & $29^{\circ} \mathrm{C} \mathrm{\&} 31^{\circ} \mathrm{C}$ \\
Pour Point & $<-20^{\circ} \mathrm{C}$ \\
Cloud Point & $<-20^{\circ} \mathrm{C}$ \\
Existent Gum & $34 \mathrm{gm} / \mathrm{m}^{3}$ \\
\hline
\end{tabular}




\section{Conclusion}

Pyrolysis of PP in the presence of catalysts ZSM-5, Zeolite, RB \& SPS yields desirable liquid product together with charred coke and non-condensable gases. Among the different catalyst studied, maximum yield of $84.67 \%$ was obtained using ZSM-5 and the feed to catalyst ratio was 3:1, the optimum temperature range for PP catalytic cracking was $380^{\circ} \mathrm{C}-420^{\circ} \mathrm{C}$. Zeolite shows better substitute as catalyst because Zeolite converts PP into liquid yield $60.00 \%$ under the same $\mathrm{F} / \mathrm{C}$ ratio and temperature range as ZSM-5. There was no liquid yield observed below $330^{\circ} \mathrm{C}$ and above $425^{\circ} \mathrm{C}$ the product was essentially non-condensable. Conversion of PP to liquid fuel will not only resolve the problem of disposal but also give a value aided product.

\section{References}

[1] Vyas, A., Singh, S.K. and Lalwani, G.K. (2015) Pyrolysis of PE Using the Various Catalysts. International Journal of Advanced Chemical Research, 4, 39-43.

[2] CPCB. Plastic Waste Management. http://www.cpcb.nic.in/Highlights/2007/139-144.pdf

[3] Adrados, A., de Marco, I., Caballero, B.M., López, A., Laresgoiti, M.F. and Torres, A. (2011) Pyrolysis of Plastic Packaging Waste: A Comparison of Plastic Residuals from Material Recovery Facilities with Simulated Plastic Waste. Waste Management.

[4] Dou, B., Park, S., Lim, S., Yu, T.-U. and Hwang, J. (2007) Pyrolysis Characteristics of Refuse Derived Fuel in a PilotScale Unit. Energy Fuels, 21, 3730-3734. http://dx.doi.org/10.1021/ef7002415

[5] Brandrup, J., Bittner, M., Michaeli, W. and Menges, G. (1996) Recycling and Recovery of Plastics. Carl Hanser Verlag, Munich and New York.

[6] Grause, G., Matsumoto, S., Kameda, T. and Yoshioka, T. (2011) Pyrolysis of Mixed Plastics in a Fluidized Bed of Hard Burnt Lime. Ind. Eng. Chem. Res., 50, 5459-5466. http://dx.doi.org/10.1021/ie102412h

[7] Lin, H.-T., Huang, M.-S., Luo, J.-W., Lin, L.-H., Lee, C.-M. and Ou, K.-L. (2010) Hydrocarbon Fuels Produced by Catalytic Pyrolysis of Hospital Plastic Wastes in a Fluidizing Cracking Process. Fuel Processing Technology, 91, 1355-1363. http://dx.doi.org/10.1016/j.fuproc.2010.03.016

[8] Scheirs, J. and Kaminsky, W. (2006) Feeds Stock Recycling and Pyrolysis of Waste Plastics: Converting Waste Plastics into Diesel and Other Fuels. John Wiley \& Sons. http://dx.doi.org/10.1002/0470021543

[9] Wang, J.-L. and Wang, L.-L. (2011) Catalytic Pyrolysis of Municipal Plastic Waste to Fuel with Nickel-loaded Silicaalumina Catalysts. Energy Sources, Part A, 33, 1940-1948. http://dx.doi.org/10.1080/15567030903436814

[10] Sancho, J.A., Aznar, M.P. and Toledo, J.M. (2008) Catalytic Air Gasification of Plastic Waste (Polypropylene) in Fluidized Bed. Part I: Use of in-Gasifier Bed Additives. Ind. Eng. Chem. Res., 47, 1005-1010. http://dx.doi.org/10.1021/ie071023q

[11] Arandes, J.M., Abajo, I., Lpez-Valerio, D., Fernndez, I., Azkoiti, M.J., Olazar, M. and Bilbao, J. (1997) Transformation of Several Plastic Wastes into Fuels by Catalytic Cracking. Ind. Eng. Chem. Res., 36, 4523-4529. http://dx.doi.org/10.1021/ie970096e

[12] Sojáka, L., Kubineca, R., Jurdákováa, H., Hájekováb, E. and Bajusb, M. (2006) GC-MS of Polyethylene and Polypropylene Thermal Cracking Products. Petroleum \& Coal, 48, 1-14.

[13] Tang, L., Huang, H., Zhao, Z.L., Wu, C.Z. and Chen, Y. (2003) Pyrolysis of Polypropylene in a Nitrogen Plasma Reactor. Ind. Eng. Chem. Res., 42, 1145-1150. http://dx.doi.org/10.1021/ie020469y

[14] Siddiqui, M.N. and Redhwi, H.H. (2009) Pyrolysis of Mixed Plastics for the Recovery of Useful Products. Fuel Processing Technology, 90, 545-552. http://dx.doi.org/10.1016/j.fuproc.2009.01.003

[15] Sarker, M., Rashid, M.M., Molla, M. and Rahman, M.S. (2012) Un-Proportional Municipal Waste Plastic Conversion into Fuel Using Activated Carbon and HZSM-5 Catalyst. Journal of Applied Chemical Science, 4, 1-8. 